\title{
ETIK, HUKUM DAN SOSIAL PADA PENANGANAN INFERTILITAS
}

\author{
Rajuddin $^{1}$, Ali Baziad ${ }^{2}$ \\ ${ }^{1}$ Bagian Obstetri dan Ginekologi, Fakultas Kedokteran Universitas Syiah Kuala \\ ${ }^{1}$ Bagian Obstetri dan Ginekologi, Fakultas Kedokteran Universitas Malikussaleh \\ ${ }^{2}$ Bagian Obstetri dan Ginekologi, Divisi Endokrinologi Reproduksi Fakultas Kedokteran Universitas Indonesia \\ Corresponding Author : rajud88@gmail.com
}

\begin{abstract}
Abstrak
Pasangan suami isteri akan menempuh segala cara untuk mendapatkan keturunan, karena keturunan adalah anugerah yang dititipkan tuhan kepadanya. Bila pasangan suami isteri sudah berusaha tetapi keturunan belum mereka peroleh atau disebut infertilitas, maka usaha untuk memperoleh keturunan akan dilakukan mulai dari teknik sederhana sampai yang menggunakan teknologi yang canggih serta modern, namun tetap saja angka keberhasilan nya masih rendah. Dewasa ini telah diciptakan suatu metode untuk membantu para pasutri mendapatkan keturunan, yaitu dengan cara Assisted Reproductive Technology (ART), atau artinya dalam bahasa Indonesia Teknologi Reproduksi Berbantu. Salah satu metode ART adalah in vitro fertilization (IVF), atau yang dikenal dikalangan dokter maupun orang awam adalah Bayi Tabung . Dari semua cara penanganan infertilitas, maka ART banyak menimbulkan masalah etik, hukum dan sosial.
\end{abstract}

Kata kunci: infertilitas, ART, assisted reproductive technology, etika.

\section{ETHICS, LAW AND SOCIAL HANDLING OF INFERTILITY}

\begin{abstract}
Married couples will pursue all means to obtain children, because the descent is a gift that God entrusted to him. When couples have tried but the children they have not obtained or called infertility, then the effort to get the children will be done from simple techniques to using sophisticated technology and modern, but still its success rate is still low. Nowadays a method has been devised to help couples get children, by means of Assisted Reproductive Technology (ART), or meaning in Indonesian Reproductive Technology. One method of antiretroviral therapy is in vitro fertilization (IVF), or known among physicians as well as lay people as Baby Tubes. Of all the ways of handling infertility, then ART causes many ethical, legal and social problems
\end{abstract}

Keyword : infertility, ART, assisted reproductive technology, ethics 


\section{PENDAHULUAN}

Sudah merupakan kenyataan, bahwa hampir semua pasutri terutama di Indonesia menginginkan keturunan. Berbagai cara ditempuh agar cepat mendapatkan keturunan. Ada diantara pasutri yang cepat mendapatkan keturunan, namun ada juga yang sulit mendapatkan nya, bahkan sudah bertahun-tahun berusaha tak kunjung mendapatkan keturunan. Mungkin manusia lupa bahwa sesuatu apapun didunia ini ada yang mengatur. Sebagaimana firman Tuhan " Sesungguhnya keadaan nya apabila Dia menghendaki sesuatu,hanya lah berkata kepada nya" jadilah " maka jadi lah ia ( (QS Yaa Siin 36:43)". Kepunyaan Allahlah kerajaan langit dan bumi. Dia menciptakan apa yang Dia kehendaki., Dia memberikan anak- anak perempuan kepada siapa yang Dia kehendaki, dan Dia memberikan anak- anak laki kepada siapa yang Dia kehendaki. Atau Dia menganuhgerahkan kedua jenis laki- laki dan perempuan dan Dia jadikan mandul siapa yang Dia kehendaki.. Sesungguhnya Dia lah maha Mengetahui lagi Maha Kuasa (QSAssyura, 42:50)

Berbagai cara telah dikembangkan oleh para ahli di dunia ini agar para pasutri bisa mendapatkan keturunan. Mulai dari yang sederhana sampai yang menggunakan teknologi yang canggih serta modern, namun tetap saja angka keberhasilan nya masih rendah. Dewasa ini telah diciptakan suatu metode untuk membantu para pasutri mendapatkan keturunan, yaitu dengan cara yang dikenal sebagai istilah Assisted Reproductive Technology (ART), atau artinya dalam bahasa Indonesia Teknologi Reproduksi Berbantu. Salah satu metode ART adalah in vitro fertilization (IVF), atau yang dikenal dikalangan dokter maupun orang awam adalah Bayi Tabung. IVF telah memberikan harapan pada jutaan pasutri yang belum mendapatkan anak.sejak lahir bayi pertama tahun 1978 dari program IVF yang diberi nama LOISE Broun ${ }^{(1)}$ Seluruh dunia lebih dari 70 juta pasutri infertil. (2). Pada tahun 2009, 3,4 juta anak lahir seluruh dunia dari metode IVF.

\section{Dampak Assisted Reproductive Technology}

Dari semua cara penanganan infertilitas, maka ART yang banyak menimbulkan masalah etik, hukum dan sosial. The American Society For Reproductive Medicine (ASRM) memberikan beberapa contoh dalam teknik ART yang menimbulkan masalah etik, hukum dan sosial, diantaranya adalah: ${ }^{2}$ 
1. Kehamilan ganda. Praktisi bayi tabung berusaha agar angka keberhasilan meningkat. Salah satu cara adalah dengan menstransfer labih dari satu embrio. Di Europa pada tahun 2006, satu embrio yang ditransfer sebanyak 22\%, dua embrio sebanyak 57\%, tiga embrio sebanyak $19 \%$ dan empat embrio sebanyak 1,6\%. Bila dua atau tiga embrio yang di transfer ternyata berhasil dibuahi dan terus tumbuh, maka biasanya bayi yang dilahirkan berat badannya rendah atau lahir prematur (OR 1.26,95\% CI 1.10-1.44). dan meningkat kejadian cacat pada bayi ${ }^{(3)}$. Risiko lahir kecil untuk usia kehamilan meningkat (OR 1.26, 95\% CI 1.10 -1.44) pada bayi yang lahir melalui ART. Disinilah timbul masalah etik, hukum dan sosial.Masalah etik berkaitan dengan perawatan bayi kecil yang memerlukan waktu lama dan biaya yang harus dikeluarkan untuk merawat bayi kecil cukup besar, padahal ongkos yang harus di keluarkan mengikuti proses bayi tabung bukan kecil. Misalnya di USA biaya IVF persiklus USD 9,266. Namun biaya yang harus dikeluarkan untuk IVF sampait bayi lahir hidup di USA 33.000, di canada USD 41.000, di Scandinavia, Jepang dan Australia antara USD 24.000 sampai USD $25.00{ }^{(4,5)}$. Di Jakarta rata - rata biaya IVF 100.000 IDR ( bervariasi). Bila sampai bayi kecil yang dilahirkan meninggal, pasien dapat menempuh jalur hukum. Oleh karena itu perlu diberikan imformed consern yang etis,adekuat dan jujur. Masalah sosial dapat muncul berupa perawatan bayi di rumah yang lama dan timbulnya masalah kesehatan pada bayi. Pasutri selain telah mengeluarkan biaya yang besar untuk proses IVF, juga harus mengeluarkan biaya perawatan bayi kecil. Asuransi di banyak negara tidak menanggung penobatan infertilitas ${ }^{(4)}$. Oleh karena itu praktisi bayi tabung harus berpikir ulang untuk tidak menstranfer embrio lebih dari satu. Masalah ertik lain adalah tidak cukup tersedianya klinik atau rumah sakit tempat masyarakat mencari pertolongan masalah infertilitasnya, terutama penanganan IVF, sehingga terpaksa pergi ke negara lain, menembus batas sebuah negara yang dikenal dengan istilah" Cross- border reproductive care " (6).

Kadang kadang tidak semua embrio di transfer, sisanya dibekukan agar dapat digunakan dilain hari. Andaikata sekali transfer berhasil, maka apa yang akan dilakukan dengan sisanya, tentu akan disimpan dengan pembekuan. Masalah etik akan muncul bila pada saat penyimpanan terjadi kerusakan pada embrio, atau bagaimana kalau yang punya embrio meninggal dunia, atau bercerai, atau pindah tempat tinggal yang sulit di ketahui alamatnya. Hal ini semua harus dijelaskan sejak awal pasien memutuskan untuk membekukan embrionya.

Apakah bayi yang lahir dari ART seperti IVF berdampak negatif di kemudian hari?. Pertanyaan ini masih menimbulkan silang pendapat di kalangan ahli. 25 penelitian yang dilakukan dengan 
metaanalisis menemukan 25\% meningkatkan risiko defek pada bayi- bayi yang lahir dengan proses IVF, sedang metaanalisis yang lain menemukan peningkatan signifikan risiko defek pada bayi sebanyak $30-40 \%$ bila di bandingkan dengan bayi lahir tanpa mengikuti $\operatorname{IVF}^{(3,7,8,9,10)}$. Davies et al pada tahun 2012 juga menemukan risiko defek pada bayi meningkat signifikan yang lahir dari proses IVF sebanyak 8,3 \% ( 513/6163) dibandingkan yang lahir tanpa IVF yaitu 5,8\% ( 17546/302811) OR 1.47,95\% CI 1.33-1.62, multivariat- adjusted OR 1.28, 95\% CI 1.16-1.41 (11).

Ditemukan peningkatan beberapa jenis kanker pada bayi yang lahir dari IVF. Ditemukan meningkatnya kelainan epigenetik pada bayi yang lahir dari proses IVF dan akibat epigenetik ini diduga menyebabkan timbulnya beberapa jenis kanker ${ }^{(12,13)}$. Penelitian di Belanda menemukan peningkatan kanker retinoblastoma pada bayi yang lahir dari IVF antara tahun 1995-2002 (RR 4,9, 95\%, CI 1,6-11,3) ${ }^{(14)}$. Namun penelitian di Perancis menyimpulkan tidak ada hubungannya kejadian retinoblastoma dengan IVF ${ }^{(15)}$. Penelitian yang dilakukan berdasarkan registrasi pada 26.692 kasus IVF menemukan sebanyak $42 \%$ meningkatnya risiko kanker yang berkaitan dengan proses IVF, dan penelitian yang lain pada 2830054 kasus melaporkan sebanyak 18\% risiko kanker yang ada kaitannya dengan masalah infertilitas maternal, artinya kejadian kanker tidak semata mata karena pengaruh IVF melainkan juga karena faktor ibu ${ }^{(16,17)}$. Sayangnya ke dua penelitian tersebut tidak menyebutkan metodologi ART dan waktu observasinya juga pendek pasca ART. Penelitian yang lain juga tidak menemukan peningkatan risiko kanker secara keseluruhan, namun meningkatkan risiko leukemia, lymphoma hodgkin baik IVF konvensional maupun IVF dengan ICSi( intracystoplasmic sperm injection) ${ }^{(18)}$. Laporan dari Yunani dan Swedia berdasarkan hospital based case- control study menemukan bahwa IVF berkaitan dengan meninkatnya risiko awitan dini akut lipoblastik leukemia. Risiko leukemia diamatin selama 3,8 tahun dan dibandingkan dengan kontrol (OR $2.2195 \%$ CI 1,27-3,85) ${ }^{(19)}$.

\section{Masalah yang timbul dari IVF}

Selain masalah masalah di atas, ternyata masih ada lagi masalah kesehatan yang dapat dijumpai pada bayi-bayi yang lahir dari proses IVF. Pada saat mencapai usia dewasa ditemukan ada yang terkena penyakit cardiovasculer ${ }^{(20,21)}$. Anak yang lahir dari IVF usia 8-18 tahun ditemukan tekanan darah tinggi dan kadar glukosa yang juga tinggi bila dibandingkan dengan anak yang lahir bukan dari $\operatorname{IVF}^{(20,21,22)}$. Penelitian menemukan vaskularisasi retina yang 
abnormal pada anak yang lahir dengan metode intracytoplasmic sperm injection ${ }^{(20)}$. Di bidang neurologi ditemukan cerebral palsi pada anak anak yang lahir melalui IVF dibandingkan dengan anak yang lahir yang tidak melalui IVF $^{(23,24,25)}$. Tidak ditemukan gangguan pada pertumbuhan gonad pada anak usia 8-14 tahun prepubertal maupun pubertal, testis dan penis normal, konsentrasi Anti Mullerian Hormon (AMH) dan kadar Inhibin B juga normal ${ }^{(26,27)}$. Pada tahun 2012 analisa dari 46 penelitian menemukan peningkan risiko sistim saraf (RR 2,01), risiko sistim urogenital (RR 1,69), sistim digestif (RR 1,66), sistim sirkulasi (RR 1,48), mata, telinga, muka dan leher $\left(\operatorname{RR}(1,43){ }^{(10)}\right.$. Ditemukan gejala perubahan perilaku dan kecenderungan depresif ${ }^{(28)}$. Kejadian autisme atau autisme spektrum disorders (ASDS) ditemukan tinggi pada anak-anak yang lahir setelah ICSI ${ }^{(29)}$, namun sistematik analisa yang di lakukan oleh Hvidjorn dkk hasilnya inkonsisten $^{(30)}$.

Setiap pasutri tentu menginginkan anak yang dilahirkan tanpa cacat genetik, karena bila sampai terjadi maka tidak mungkin lagi dapat dilakukan apa pun pada anak tersebut. Dewasa ini telah dapat dilakukan Prenatal Gestasional Diagnostik(PGD), artinya sebelum embrio di transfer diambil bagian kecil dari embrio dan dilakukan pemeriksaan gen. Hanya embrio yang tidak ditemukan kelainan genetik saja yang di transfer. Timbul masalah etik dikemananakan embrio yang memiliki kelainan genetik tersebut?. Di musnahkan atau digunakan untuk riset. Disini timbul dilema etik. UU Kesehatan no 36 tahun 2009 di iIndonesia memperbolehkan pengakhiran kehamilan pada keadaan ditemukan kelainan bawaan yang berat pada bayi dalam kandungan,yang oleh para ahli dinyatakan bayi tersebut kecil sekali kemungkinan hidup. Namun pendapat agama berbeda beda. Ada agama yang melarang terminasi kehamilan, bahkan melarang dilakukan apapun terhadap embrio, karena embrio sudah merupakan suatu kehidupan dan telah memiliki aspek hukum, berarti melakukan sesuatu atau memanipulasi embrio akan berurusan dengan hukum.Masalah etik lain yang berbahaya adalah memungkinkan melakukan seleksi tender yang tentu akan berdampak ke masalah sosial, dimana di suatu negara bisa saja penduduknya semua laki-laki atau semua perempuan

Dengan kemajuan teknologi pasutri sudah dengan mudah mendapatkan keturunan dewasa ini. Tidak perlu lagi berobat ke dokter. Cukup membeli embrio yang sudah jadi yang sudah di seleksi ada kelainan genetik atau tidak. Di Indonesia tidak dibenarkan jual beli embrio, sel telur maupun sperma, namun di beberapa negara maju hal tersebut tidak dilarang, sehingga banyak pasutri yang melancong sebagai turis dan pulang telah hamil ( Turism Reproduction). Dengan 
tersedianya embrio yang sudah jadi dan dapat di beli, maka pasangan lesbian maupun homoseksual memungkinkan untuk hamil.

Bagi perempuan yang ovariumnya rusak mungkin akibat kemoterapi maupun radiasi dewasa ini sudah tidak ada masalah lagi untuk mendapatkan keturunan, karena telah dapat dilakukan transplantasi ovarium. Sebelum kemoterapi atau radiasi dilakukan, diambil jaringan ovarium dan dibekukan untuk digunakan kemudian dengan cara transplantasi. Pada tahun 2008 telah dapat dilahirkan bayi dari hasil transplantasi ovarium melalui proses $\operatorname{IVF}^{(31,32)}$.

Dari semua penjelasan di atas dapat disimpulkan bahwa ternyata IVF memberikan dampak negatif terhadap anak dikemudian hari, miskipun kejadiannya kecil dan masih menimbulkan silang pendapat, akan tetapi fakta tersebut ada. Kelainan kelainan yang ditimbulkan akibat proses IVF sedikit sekali ditemukan pada anak yang lahir tanpa mengikuti proses IVF. Para praktisi IVF sudah harus mencari jalan keluar agar anak- anak yang dilahirkan tidak mendapatkan kelainan yang akan dialaminya sepanjang hidupnya. Para dokter yang menggunakan teknik IVF harus memiliki kompetensi, tidak cukup hanya sekedar telah mengikuti seminar - seminar atau workschop saja. Sesuai dengan UU praktik kedokteran no 29 tahun 2004, pasal 29 yang berbunyi setiap dokter dan dokter gigi yang melakukan praktik kedokteran di Indonesia harus memiliki sertifikat kompetensi. Sertifikat kompetensi di keluarkan oleh kolegium.

Islam mengajarkan kita tidak boleh berputus asa dan tetap harus berusaha. Islam memperbolehkan IVF asal sperma dan ovum berasal dari suami dan istri yang sah. Bila sperma dan ovum nya bukan dari pasutri yang sah maka hukum nya haram dan status zina. Hadits Nabi Muhammad SAW, tidak halal bagi seseorang yang beriman kepada Allah Dan hari akhir menyarankan air nya (sperma) pada tanaman orang lain ( HR Abu Daud, Thirmidzi).

\section{DAFTAR PUSTAKA}

1. Steptoe PC, Edwards G. Birth after reimplant of human embryo. Lancet 1978 vol 28085

2. Ombelet W, Cooke I, Dyer S, Serous G. Infertility and and the provesion of infertility and medical in developing countries. Hum Reprd 2008;14:605-21

3. Hansen M, Bower C, Milue E, de Klerk N,Kurinczuk JJ. Assisted reproductive technologies and the risk of brth defect: a systematic review. Hum Reprd 2005;20:328-38 
4. Lediger WL, Anumba D, Mailon N, Thomas CM, Wilson EC. The Cost to the NAS of multipel birts defects after IVF treatment in UK. J obstet Gynecol 2006;13: 21-25

5. Chambers GM, Sullivan EA, Ichihara O, Chapman MG, Adamson GD. The economic impact of assisted reproductive technologie. : A review at selected developed countries. Fertil Steril 2009;91:2281-94

6. Paul R, Yulian Z. The etical, legal and sosial issues impact by modern assisted reproductive technologies. Obstet Gynecol Intern 2012;12:6825

7. Rimm AA, Katayama AC, Diaz M, Katayama KP. Meta-analysis of controlled studies compary mayor malformation rates in IVF and ICSI infants with naturally conceived children. J Assit Repro Genet 2004;12:437-43

8. Olivennes F. Do children born after assisted reproductive technology have a higher incidence of berth defects?. Fertil Steril 2005;84:1325-26

9. Shieve LA, Rasmussen SA, Reefhuis J. Risk of birth defects among children conceived with assisted reproductive technology: providing an epidemiologic context to the data. Fertil Steril 2005;84: 1320-24

10. Wen J, Yiang J, Ding C, Dai J, Liu Y, Xia Y, Hu Z. Birth defects in children conceived by in vitro fertilization and intracystoplasmic sperm injection: a meta- Analysis. Fertil Steril 2012;97:1331-37

11. Davies MJ, Moore VM, Willson KJ, van Essen P, Priest K, Scott H, Han FA, Chan A. Reproductive technologies and the risk of birth defects. N Engl J Med 2012;366:1803-13

12. Tomizawa S, Sasaki H. Genomic Imprinting and its relevance to congenital disease, infertility, molar pregnancy and induced pluripotent stem cell. J Hum Genet 2012;57:84-91

13. Choo KB. Epigenetik in disease and cancer. Malays J Pathol 2011;33:61-70

14. Moll AC, in hoof SM, Cruysberg JR, Schouten VM, Meetersen AY, Boers M,van Leeuwen FE. Incidence of retinoblastoma in children born after in vitro fertilization. Lancet 2003;36:309-10

15. Foik -L-Le Ronic, Gauther-Vilars M, Lebrune P, Bouyer J etal. Are children born after infertility treatment increased risk of retinoblastoma?. Hum Reprd 2012;27:2186-92

16. Kallen B, Finnstrom O, Lindaw A, Nillson E, Nygren KG, Olansson PO. Cancer risk in children and young adults conceived by in vitro fertilization. Pediatrics 2010;126:270-76 
17. Hargreave M, Jensen A, Deltour I, Brinstrom LA, Andersen KK, Kyaer SK. Increased risk for cancer among offspring of women with fertility or problems. Int $\mathrm{J}$ Cancer 2013;137:2015-61

18. Reigstad MM, Larsen IK, Myklebust TA etal. Risk of cancer in children conceived by assisted reproductive technology. Pediatric s 2016;137:2015-61

19. Peridou ET, Segentanis TN, Panagopoulow P, Moshovi M, Polychronopouws, Buka M etal. In vitro fertilization and risk of childhood leukemia in Greece and Swedia. Pediatric s Blood Cancer 2012;58:930-36

20. Ceelen M, van Weissenbruch MM, Vermeiden JP, van Leeuwen FE, Delemarre van der Waal HN. Cardiometabolic differences in children born after in vitro fertilization follow up study. J Clin Endocrinol Metab 2008;93:1682-88

21. Wikstrand MHZ, Niklasson A, Stromland K, Hellstrom A. Abnormal vessel morphology in born after intracystoplasmic sperm injection. Acta Pediatric 2008;97:1512-17

22. Culen M, van Weissenbruch MM, Prein J, Smitt JJ, Vermeiden JP, Spreenwenberg M, van Leeuwen FE. Growth during infancy and early childhood in relation to blood pressure and body fat measures at age 8-18 years of IVF children and spontaneously conceived controls born to subfertile parents. Hum Reprod 2009;24:2788-95

23. Stromberg B, Dahlgnist G, Ericson A, Finnstrom O, Koster M, Stjrugvist K. Neurological sequelae in children born after in vitro fertilization: a population based study. Lancet 2002;359:461-65

24. 24 KlettinR, Swon T, Gissler M, Hemminki E. Health of children born as a result of in vitro fertilization. pediatrics 2006;118:1819-27

25. Kallen B, Finnstrom O, Lindan A, Nilsson E, Nygren KG, Olausson PO. Trend in delivery and neonatal outcome after in vitro fertilization in Sweden: data for 25 years. Hum Reprod 2010;25:1026-34

26. De Schepper J, Belva F, Schettecatte J, Anckaert E, Tournaye H, Bonduelle M. Testicular growth and tubular function in prepubertal boys conceived by ICSI. Hum Res 2009;71:359-63

27. Belva F, Roelants M, Painter R, Bounduelle M, Devroej P, de Shepper J. Pubertal development in ICSI children. Hum Reprod 2012;27:1156-61 
28. Wagenaar K, van Weisenbruch MM, van Leeuwen FE, Kettenis PT, Delemarre-van der Waal HA, Schats R. Self-reported behavior and socioemotional functioning of 11-18 yearsold adolescents conceived by in vitro fertilization. Fertil Steril 2011;95:611-16

29. Knoster M, Helmerhorst FM, Vandenbrouch JP, Wisserlaken IA, Walther FJ, Veen S. Perinatal outcome, health, growth and medical care utilization of 5-to-8 year old intracystoplasmic sperm injection singletons. Fertil Steril 2008;89:133-46

30. Hividjorn D, Schieve L, Shendel D, Jacobsson B, Svaerke C, Thorsen P. Cerebralpalsy, autism spectrum disorders, and development delay in children born after assisted conception:a systematic review and metaanalisis. Arc Pediatr Adolesc Med 2009;163:7283

31. ASRM Ethnics Committee Report. Fertility preservation and reproductive in cancer patients. Fertil Steril 2005;83:1622-28

32. Mirror D. Fertility preservation in cancer using stored ovarian tissue clinical aspects. Current opinion in endocrinilogy, diabetes and obesity.2008;15:536-47 